\title{
El arte en el discurso de los tatuadores
}

\section{Art in the discourse of tattooists}

\author{
Alejandra Walzer-Moskovic \\ Facultad de Humanidades, Comunicación y Documentación. Universidad Carlos III. Madrid. \\ awalzer@hum.uc3m.es
}

Recibido: 31 de julio de 2014

Aprobado: 17 de noviembre de 2014

\begin{abstract}
Resumen
El tatuaje constituye una práctica humana que se puede rastrear desde tiempos lejanos en culturas remotas, pero en las últimas décadas se ha convertido en una experiencia mainstream en sociedades occidentales urbanas. Esta novedad va de la mano de modificaciones en su estatus y características. Entre ellas cabe mencionar la profesionalización y la llegada de personas provenientes de diversos campos de las artes plásticas así también como la extensión del tatuaje entre las clases medias. Para hacer una referencia a la relación entre tatuaje y arte se parte de la dificultad teórica para circunscribir y consensuar en la actualidad una definición aceptada de arte de carácter general pero también de la relevancia que, con manifestaciones diversas, ha tenido el cuerpo en las artes visuales a lo largo de siglos. Esto constituye un argumento de interés en tanto el tatuaje consiste en una inscripción icónica o lingüística sobre el cuerpo. El objeto de este trabajo no es concluir si el tatuaje puede ser definido como actividad artística sino indagar cómo aparece el arte corporal en el discurso de tatuadores y tatuadoras. Para ello se han realizado entrevistas en profundidad tanto en Estados Unidos como en España.
\end{abstract}

Palabras clave: arte, cuerpo, tatuaje, tatuadores.

Walzer-Moskovic, A. (2015): El arte en el discurso de los tatuadores. Arte, Individuo y Sociedad, 27(3) 463-481

\begin{abstract}
Tattoo is a human practice that can be traced from ancient times in remote cultures, but in recent decades it has become a mainstream experience in urban western societies. This development goes hand in hand with changes in its status and characteristics that must be considered. Among them, the professionalisation of the practice and the arrival of people from various fields of the arts as well as the extension of tattoo to the midd classes. To make a reference to the relationship between art and tattoo we must consider the theoretical difficulty to agree and circumscribe an accepted definition of art today but also must consider the relevance of the body in the visual arts over centuries. This is an argument of interest because tattoo is an iconic or linguistic inscription in the body. The purpose of this paper is not, therefore, to conclude whether tattoo can be defined as an artistic activity or not but to investigate the way how art and body issues show up in the discourse of tattoo artists. To achieve this goal, in depth interviews were carried on in the United States and in Spain.
\end{abstract}

Keywords: art, body, tattoo, tattoists. 
Sumario: 1. En torno a la definición de arte, 2. Sobre el tatuaje, el arte y el cuerpo, 2.1. Tatuaje contemporáneo, 2.2. El cuerpo y el arte, 3. Planteamiento de la investigación, 4 . El tatuaje en el discurso de tatuadores y tatuadoras, 4.1. Inicios profesionales, 4.2. ¿Arte, artesanía, profesión, oficio?, 4.3. Tatuaje y autoría, 4.4.Analogías entre tatuaje y artes visuales, 4.5. Lo específico del tatuaje, 5. Conclusiones. Referencias.

Este texto forma parte de una investigación más extensa realizada gracias a las "Ayudas de Movilidad para profesores en Universidades de reconocido prestigio" concedida por la Universidad Carlos III de Madrid y que se desarrolló en Columbia University, School of Arts en la ciudad de New York durante el período: febrero-mayo de 2013.

\section{En torno a la definición de arte}

Como explica Hans Belting (2007), no toda imagen constituye una obra artística. Se trata de una afirmación evidente y, al mismo tiempo, necesaria en un entorno icónico como el actual recargado por imágenes de todo tipo: informativas, publicitarias, artísticas, de moda, personales, institucionales, etc. No solo la cantidad y tipo de imágenes ha aumentado de forma notoria sino que además los soportes y medios en los que se ofrecen se han multiplicado y diversificado. También es posible verificar transformaciones en lo relativo a la autoría y los públicos, las intencionalidades comunicativas y las formas de producción y distribución.

Ahora bien, ¿cuáles son las imágenes que pueden ser consideradas arte? Esta pregunta no tiene fácil respuesta en la actualidad o quizás no tenga ninguna. La determinación de qué es lo que puede ser incluido dentro del campo artístico encuentra desde hace ya varias décadas una difícil delimitación. Diferentes autores han puesto el acento en aspectos diversos: la imaginación, el gozo que produce una obra o el sentimiento estético que en su caso estimule, la intencionalidad o la forma de trabajo del creador, la adscripción a una escuela, la capacidad para aportar o producir conocimiento, la verdad que alberga, el valor en el mercado, el reconocimiento de los expertos, la capacidad innovadora, etc.

La noción de Bellas Artes que se ha usado durante al menos cuatro siglos ha sido una forma de cobijar un conjunto de producciones bajo una categoría común. Se trata de una denominación que no es neutra. En primer lugar porque incluye la categoría de lo bello vinculada a las artes y también porque delimita un repertorio de actividades y sus productos que pueden considerarse como parte de las Bellas Artes dejando fuera a otras que no son consideradas mayores y que, en contraposición, se nombran, por ejemplo, como artes aplicadas. Estas denominaciones establecen jerarquías y así, por ejemplo, la escultura primaría sobre otras como la ebanistería. Esta nueva denominación retoma una vieja dicotomía: la de poiesis y techné que desde la antigüedad occidental postula la existencia de artes mayores (poesía, música) y artes menores (artes plásticas).

En el devenir del trabajo de los artistas y en el del propio campo del arte, se han admitido con el tiempo obras que subvertían aquello que antaño se acomodaba en el seno de la categoría "arte", en efecto: "today's artists violate conventions once considered fundamental to art. Their work raises such questions as: is it art if it doesn't sit on a pedestal or hang on a wall? If it isn't made by the human hand? If 
it isn't the product of an inspired moment? If it isn't enduring or pleasing? If visual stimulation is not the artist's primary concern?"1 (Weintraub,1996:11). Algunos teóricos intentaron aportar claridad en este escenario confuso. Para Aumont, hay dos grupos de inconvenientes que se presentan al intentar definir el arte: una está ligada a la condición social del arte y de quienes lo realizan, es decir, los artistas, y la otra está vinculada con la diversidad de prácticas llamadas arte y la dificultad para comprenderlas como "uno solo y el mismo ejercicio de el arte" (Aumont,1998:100).

$\mathrm{Si}$ atendemos a los usos actuales del habla cotidiana de las gentes, resulta notorio cuán frecuente es nombrar como arte, artista y obra de arte a cuestiones totalmente dispares: la alta cocina, el diseño gráfico, la gracia de un humorista, las cualidades del ganador de un reality show, el toreo, el tatuaje y un largo etcétera. ¿Es un artista Messi cuando hace un gol mediante un regate sorprendente?

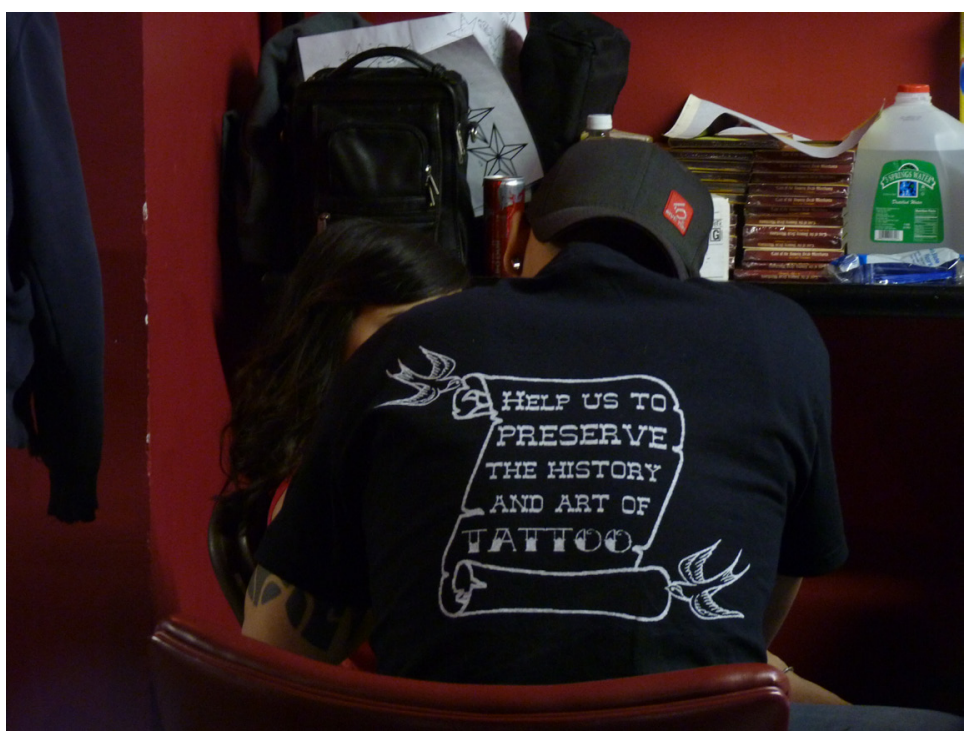

Figura 1. New York Tattoo Convention, año 2013.

Las enormes transformaciones del campo artístico, la reformulación del catálogo de las Bellas Artes a partir de la incorporación de la fotografía y del cine, la revolución de los contextos comunicativos, productivos, institucionales, de gusto, etc. nos han llevado a una situación en la que bien se podría decir que todo es arte o que ya no hay arte, pero entre estas dos formulaciones la distancia es "paradójicamente mínima" (Aumont,1998:293).

La idea de arte ha tenido a lo largo de los siglos una línea continua, pero no una línea recta (Tatarkiewicz,2002:39). En la antigüedad, por ejemplo, la palabra arte se usaba para denominar una habilidad canalizada por medio de unas reglas determinadas $\mathrm{y}$, sin embargo hoy, se usa más para nombrar un conjunto de objetos designados como obras de arte.

Arthur Danto se interroga acerca qué es el arte (2013) partiendo de la premisa de que el arte no puede ya entenderse a la manera platónica como imitación. En efecto, 
el arte contemporáneo ha desmentido la cualidad mimética como universal tal como explica en sus numerosos trabajos, especialmente los referidos a las "Caja Brillo" de Warhol y al "Urinario" de Duchamp. Y ante la pluralidad del arte Danto se empeña en no renunciar a definirlo o, al menos, a no dejarlo al albur como si de un concepto abierto se tratara y se propone encontrar cuáles son los elementos que, sin excluir su pluralidad, permiten ofrecer un concepto concreto. Pero ¿cómo distinguir qué es arte y qué no lo es? Por ejemplo: ¿qué es lo que determina la diferencia entre moda y arte si un vestido puede ser considerado como una obra de arte o como un indicador cultural?

Ninguna conceptualización ni catalogación sale indemne con las transformaciones sufridas desde la aparición de la fotografía y el cine y además, en el interior de las artes catalogadas, los propios movimientos de Vanguardia suponen una conmoción de todo orden en el interior del universo artístico. ¿Qué elementos han de tenerse en cuenta para sancionar como artística una producción? ¿existe alguna entidad, órgano, individuo autorizado a emitir un juicio atendible? La incertidumbre reina acentuada por la falta de líneas de demarcación neta entre arte, media y objetos. Como señala Tatarkiewicz (2002), resulta muy complejo establecer qué propiedades son atribuibles solo al arte. Si se sopesan los elementos multifactoriales que influyen en esta indeterminación se observará que ésta es inevitable pero, al mismo tiempo, es altamente problemática, especialmente para el campo de la investigación. En todo caso, este trabajo no pretende responder a esta pregunta crucial: ¿qué es el arte hoy?, sino dar cuenta de las dificultades con las que tropieza la pretensión de conceptualizarlo de manera abarcadora y aceptable.

Lo que sí se puede afirmar es que hay personas que trabajan produciendo obras, especialistas que valoran el trabajo, público que lo contempla, instituciones especializadas que buscan modos diversos de ofrecer al público el acceso al visionado de las obras del arte y un mercado activo.

En nuestras sociedades el arte detenta un lugar prestigioso en la configuración y en la expresión de la cultura y también es visto como algo valioso en el imaginario cultural. El lugar del arte en la era de la reproducción (mecánica o digital) continúa siendo hoy, social y culturalmente, un lugar aurático. Según Aumont (1998) esto es consecuencia de la modernidad, es decir, de un tiempo en el que la condición aurática de la obra se transfiere al arte mismo. Para Marta Zatónyi, es la cualidad hierofánica del arte la que persiste confiriéndole un lugar especial dentro del conglomerado de las producciones humanas: "esta articulación entre el valor empírico y el valor sagrado jamás dejó de existir, aun en las condiciones más adversas" (Zátonyi,2000:129)

Volvemos pues a la afirmación de Belting mencionada al inicio en la que asevera que una imagen no constituye, de suyo, una obra artística. Aun así, no se ha de perder de vista que a lo largo del tiempo se han reconocido como artísticas piezas que rompieron dramáticamente con el statu quo y que obligaron a nuevas conceptualizaciones y catalogaciones. Es momento ahora de referirse al tatuaje.

\section{Sobre el tatuaje, el arte y el cuerpo}

En las últimas décadas se ha producido un enorme auge del tatuaje, sobre todo en las sociedades urbanas occidentales ${ }^{2}$. El tatuaje constituye una producción propia 
del campo visual que involucra de forma muy significativa y peculiar al cuerpo. Por otra parte, imagen y cuerpo constituyen elementos consustanciales a las Bellas Artes de todos los tiempos. Por tanto, dada la popularización contemporánea del tatuaje, sus características actuales y la tradicional relación entre artes visuales y cuerpo, conviene desarrollar estos dos argumentos evitando toda pretensión de determinar si el tatuaje debe ser añadido al catálogo artístico y buscando conocer de qué forma el arte ha penetrado en discurso y en la práctica de los tatuadores.

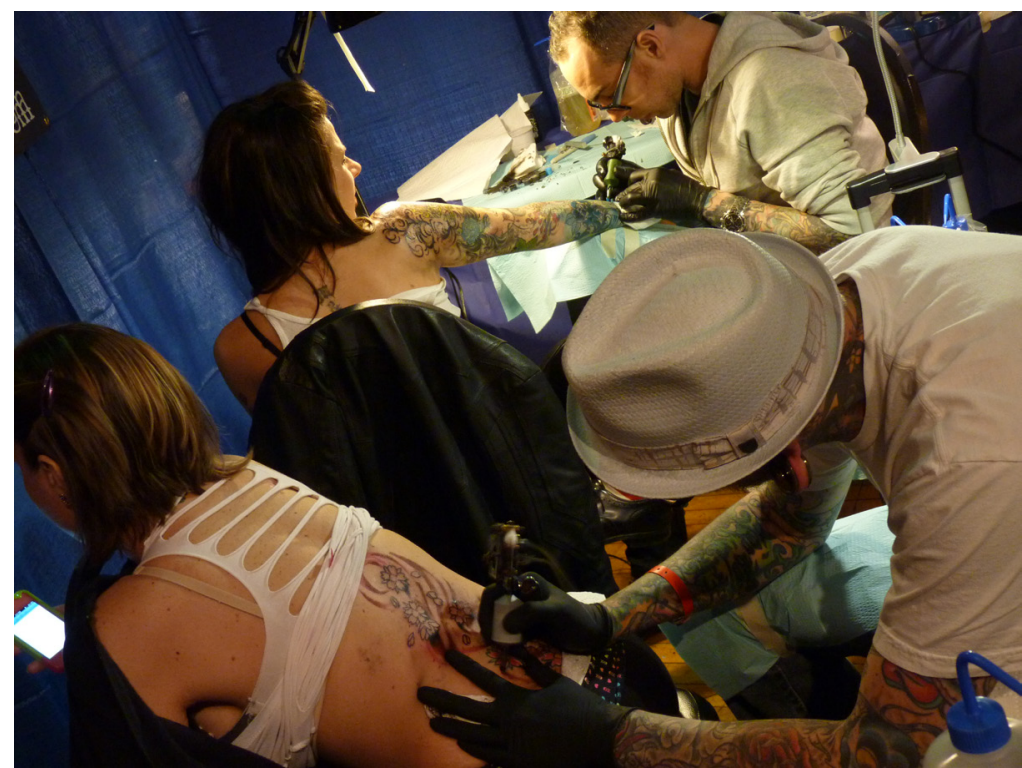

Figura 2. Escena en New York Tattoo Convention, año 2013.

\subsection{Tatuaje contemporáneo}

El tatuaje constituye una práctica ancestral con amplia tradición en sociedades humanas. Durante siglos el tatuaje tribal estuvo asociado fuertemente a lo colectivo y a lo sagrado. En estos contextos el tatuaje es una marca de lo grupal sobre el cuerpo individual. Marc Blanchard (1994) describe cuatro funciones para el tatuaje, entre ellas la identificatoria que ha sido una de las más relevantes, sirviendo tanto como elemento diferenciador de los miembros del grupo respecto de quienes no forman parte del mismo, pero también como modo de marcar el estatus personal de cada individuo dentro de su propia comunidad. El tatuaje ostenta también una función ritual, especialmente debido a su presencia en ceremonias de paso. Además, el tatuaje y el hecho de tatuarse han sido revestidos de un propósito atropopaico relacionado con su carácter mágico capaz de proteger del mal o propiciar el bien al conferirle un carácter sagrado. Finalmente, el fin decorativo y sensual también ha estado presente entre las motivaciones del tatuaje, adecuándose a lo que se considera atractivo y seductor en cada etnia.

A partir de las expediciones marítimas y de los viajes colonizadores, el mundo occidental entró en contacto con esta práctica ritual. Los viajeros, sorprendidos 
por este hallazgo comunicaban a su regreso estas costumbres asociándolas a lo "salvaje" y trayendo en sus barcos a personas tatuadas para exhibirlas ante públicos curiosos y perplejos. Como consecuencia de ello, los marinos comenzaron a tatuarse durante sus estancias allende los mares para testimoniar sus hazañas dando lugar así a la transculturación de estas prácticas. Con el tiempo, las zonas portuarias se conviertieron en el lugar en el que el tatuaje es más visible en las culturas occidentales. Más adelante, los trabajadores manuales y ciertos grupos minoritarios como los presidiarios, adoptaron el tatuaje como seña propia reinvistiendo una tradición ajena al otorgarle nuevos significados, motivos y contextos. En este caso, la asociación entre tatuaje y marginalidad quedó firmemente establecida, especialmente en Europa aunque también en los Estados Unidos, perdurando por largo tiempo.

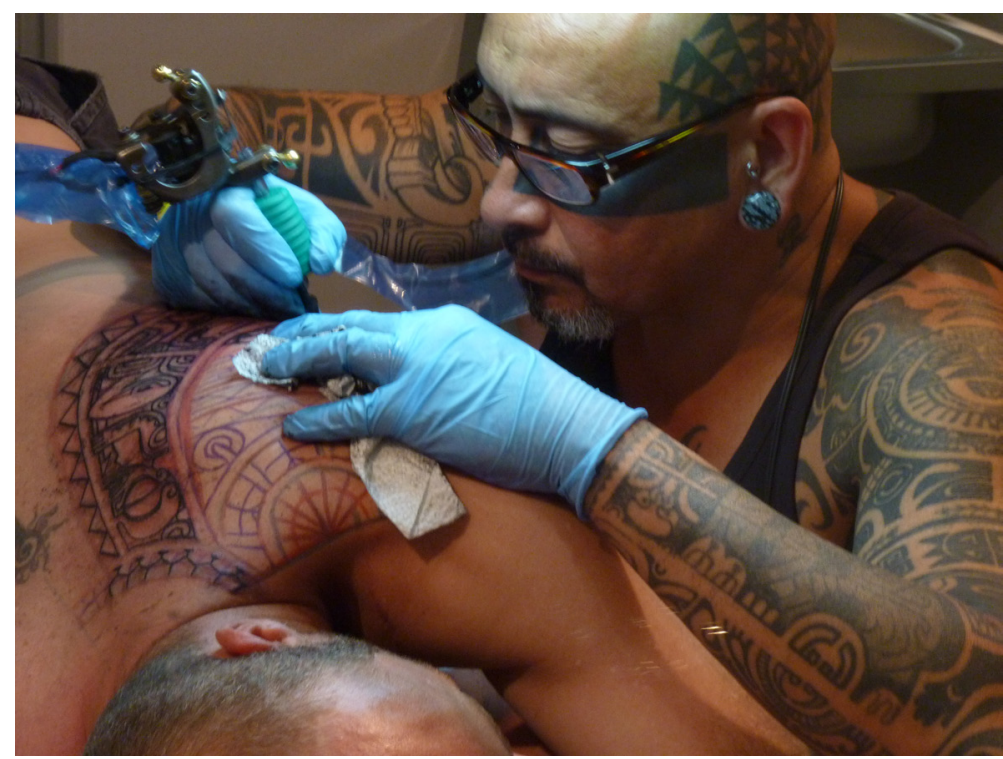

Figura 3. Chime, maestro del tatuaje polinesio.

En el siglo XX la práctica del tatuaje comenzó una transformación significativa en occidente, especialmente en los años sesenta y con más fuerza aun en los ochenta dando lugar a lo que Rubin (1987) denominó: "tattoo reinasance". Inicialmente fue de la mano de hippies y grupos contraculturales que enarbolaban banderas de movimientos políticos que reivindicaban el derecho a decidir sobre el propio cuerpo, sobre la igualdad de mujeres, los derechos de los homosexuales, etc. En este proceso, si bien el tatuaje queda asociado a determinados colectivos (fundamentalmente hippies, motoristas y rockeros), dará comienzo una nueva andadura que, con el tiempo, ha desembocado en el estado actual en el que el tatuaje se ha convertido en una marca personal de subjetivación y adorno adoptada por extensos segmentos de población. En el trayecto se produce una sanitarización del tatuaje con sus respectivas regulaciones y normas estatales, la llegada de artistas provenientes de las Bellas Artes que se interesan por esta forma de expresión, el desarrollo de nuevos diseños, géneros y estilos de la mano de la generalización de la máquina eléctrica de tatuar, la producción industrial 
de tintas de calidad, la ampliación y diversificación de población deseosa de tatuarse entre quienes se cuentan algunos famosos y famosas que exhiben públicamente sus tatuajes y que se convierten en prescriptores, las revistas especializadas, e internet. Se inicia una nueva etapa que no deja de expandirse y transformarse dando lugar a un fenómeno que es hoy fácilmente visible en innumerable cantidad de ciudades. Así el tatuaje se convierte en un modo de expresión personal que no indica necesariamente la pertenencia a un grupo étnico, social o profesional sino que se realiza como forma de expresión personal que hace del cuerpo un lugar en el cual plasmar la diferencia.

A partir de las modulaciones y transformaciones que el tatuaje ha sufrido, Margo DeMello (2000) propone una periodización que relaciona al propio tatuaje y a sus usuarios haciendo una particular consideración hacia el tipo de trabajo que la realización de esos tatuajes supone. Así, el tatuaje primitivo formaría parte de lo que ella denomina ritual work, asociado a las prácticas étnicas de culturas lejanas, al segundo estadio, relacionado con el tatuaje como práctica de grupos marginales lo denomina folk art y, por último, el correspondiente a la época actual en la que la clase media acepta y practica el tatuaje de forma notoria y correspondería al tatuaje como fine art. En esta discriminación entre ritual work, folk art y fine art, no solo se observa un cambio en la adjetivación (ritual, folk, fine), sino que también hay un cambio en el sustantivo (de work hacia art) Para esta autora, debido a que el tatuaje ya se encontraba en el pasado codificado con múltiples significaciones, necesitó, para convertirse en una forma adoptable por parte de las clases medias, sofisticarse, iluminar nuevos sentidos, difuminar algunos antiguos y crear otros (DeMello, 2000:12).

\subsection{El cuerpo y el arte}

El cuerpo humano ha sido a lo largo de los tiempos un objeto central del arte occidental, fundamentalmente a partir del Renacimiento. Desde entonces, el lugar del cuerpo en el arte ha sufrido drásticas transformaciones. No es objeto de este trabajo historizar y ejemplificar ese cambio, sin embargo resulta inevitable e imprescindible anotar aquí la significativa deriva que ha tenido el cuerpo en el arte contemporáneo, especialmente a partir de las Vanguardias. Si su expresión era inicialmente localizable en el campo de la representación y el cuerpo era el lugar en el cual expresar lo bello (fundamentalmente asociado a lo femenino), más tarde se extenderá hacia el cuerpo haciendo que ya no sea exclusivamente un objeto visual sino también un objeto carnal expresivo. La presencia del cuerpo del artista en las artes performativas y su revelación visible se hace patente de forma evidente en al arte estadounidense a partir de los años sesenta representando "profundos cambios socioculturales que hoy definimos como indicativos de la episteme 'post' moderna. El cuerpo, que en el pasado se había ocultado como confirmación del régimen de significado y valor del movimiento moderno, se ha mostrado durante este período de una forma cada vez más agresiva como un locus del yo y lugar donde el dominio público coincide con el privado, donde lo social se negocia" (Jones,2006:20). Coincide con estas apreciaciones Nicholas Mirzoeff cuando al referirse a las trayectorias del cuerpo en el arte afirma que el cuerpo "is also a central locus and metaphore for understanding and exploring political change (...) The modern period may be characterized in the regard as having an awareness that the body is mutable, incomplete and altogether 
human. This alarming feeling of instability has led to numerous efforts to control the development of the physical body by promoting certain physical characteristics at the expense of others. The postmodern sense of the body is the realization of the cost and weaknesses of such Utopian projects"3 (Miezoeff,1995:2).

La performatividad en el arte, a través de numerosos artistas (Klein, Sherman, Shneeman, Abramovich, McCarthy, Burden, Orlan, Koons, entre otros) y grupos (Gutai, Fluxus, etc.) ofrece una presentación radical del cuerpo que se hace gestual, pincel, escena, huella, que se somete a transformaciones, llevado en ocasiones hasta el límite. Así, los discursos performativos hacen referencia al cuerpo como elemento de protesta política y social, un cuerpo que es significante, que se revela. Pero también hay una referencia a la subjetivación, o más bien, a la construcción y representación del YO encarnado que "trasciende toda disquisición dualista mente-cuerpo, somapsique, materia-espíritu o cualquier otro de los pares antitéticos existentes y por todos conocidos" (Páez,2011).

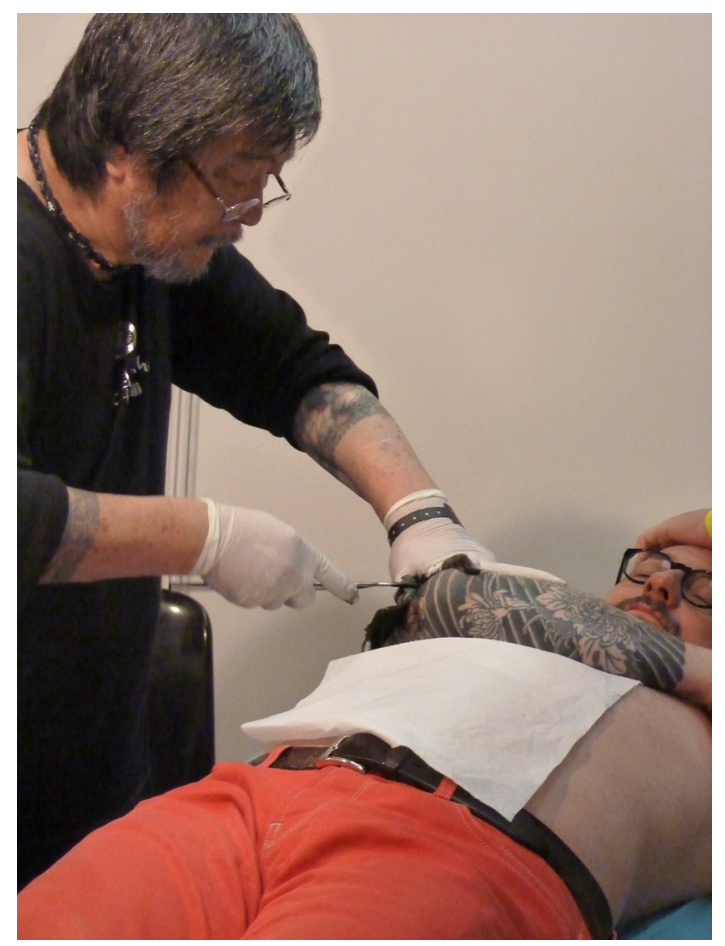

Figura 4. Horitoshi I, Maestro del tatuaje japonés.

Como explica Miezoeff el cuerpo en arte tiene el estatuto de un signo, es diferente de la carne que pretende representar, sin embargo, las representaciones del cuerpo tienen efectos sobre el cuerpo real, por ejemplo sobre que se ha de considerar aceptable o normal (Miezoeff,1995:3). En el caso del tatuaje, el cuerpo se hace representación pero, al mismo tiempo es la misma materia corporal la que soporta una expresión encarnada. Se presenta aquí una duplicación porque el cuerpo soporta los signos y se 
hace, a la vez, significante. En el tatuaje, a diferencia de las bellas artes, el cuerpo absorbe la pintura y la proyecta como una parte del sujeto aboliendo la distancia entre la imagen y su soporte (Blanchard 1994:296).

\section{Planteamiento de la investigación}

Planteados como han sido aspectos relativos al cuerpo y al arte así como al tatuaje y sus transformaciones, este trabajo se propone como objetivo general dilucidar cómo aparece la cuestión del arte en el discurso de los tatuadores. Para ello se han realizado treinta y dos entrevistas en profundidad con tatuadores (19 HTR) y tatuadoras (13 MTR). La mayor parte se realizaron en los estudios de tatuaje y muchas de ellas transcurrieron durante sesiones de tatuaje ofreciendo la posibilidad añadida de observación. Solo en un caso la entrevista se realizó en las inmediaciones del estudio. En esta ocasión, el tatuador trabajaba en uno de los llamados "supermercados del tatuaje", es decir, comercios no regenteados por un profesional sino por un empresario ajeno al ámbito. Cuatro entrevistas tuvieron lugar en Mulafest ${ }^{4}$, Expo Tattoo Barcelona y la New York Tattoo Convention. Los profesionales entrevistados cuentan con diversas trayectorias que abarcan desde la posición de aprendiz hasta la de artista internacionalmente consagrado.

Los asuntos abordados se ajustan a los objetivos específicos de este trabajo cuyo propósito es conocer a través del discurso de los tatuadores y tatuadoras cómo se expresan los siguientes asuntos: inicios profesionales; valoración del tatuaje en términos del campo artístico; autoría; analogías posibles entre el tatuaje y las artes visuales y especificidades del tatuaje frente a otro tipo de expresiones.

Es preciso hacer una aclaración idiomática y cultural antes de exponer los resultados. Dado que el trabajo se realizó en España (Madrid y Barcelona) y en Estados Unidos, (New York), conviene comentar aquí que se ha observado que en América es muy frecuente el uso de las expresiones término tattoo artist y tattoo art (aun cuando sería igualmente correcto utilizar las palabras tattoist y tattoo) otorgando así a las palabras arte y artista un lugar en la enunciación. Esta evidencia se obtiene de las páginas web de estudios de tatuaje del país de Norte América, de la revisión bibliográfica y del discurso de las personas entrevistadas. Por el contrario, en el ámbito español, las palabras usadas son tatuador/tatuadora y tatuaje. Debido a que la heterogeneidad en las formas de expresión está teñida de aspectos lingüísticos y culturales, no serán tenidas en cuenta.

\section{El tatuaje en el discurso de tatuadores y tatuadoras}

\subsection{Inicios profesionales}

Como se observará en los testimonios que siguen, muchos tatuadores y tatuadoras comentan al referirse a los inicios en el mundo del tatuaje que o bien cuentan con una formación previa o con una destreza reconocible vinculada con las artes plásticas, fundamentalmente el dibujo: "yo dibujaba como un hobby, nunca pensé que me iba a dedicar a esto" (MTR1), o: "siempre me gustó dibujar. Primero es dibujar y después tatuar" (HTR1), otro dice "dibujar me gustaba pero ni remotamente me planteé 
ganarme la vida con eso. De hecho no estudié nada referente al arte, hice dibujo muy poco de crío y después no me interesaba...Empecé a tatuar y ahí empezó un poco más de interés" (HTR3). En cambio una joven aprendiz dice: "mi formación es como restauradora pero no acabé porque química se me da fatal (...) me independicé muy prontito y para pagarme los estudios trabajaba de ilustradora, daba clases de dibujo en una academia. De ilustradora hice algo de publicidad" (MTR4) y un hombre expresa: "como dibujo bien y conozco todo: esterilizar agujas, armar máquinas y tengo todos los conocimientos necesarios que se supone que debería tener para tatuar, era como muy evidente que iba a empezar a tatuar"(MTR4), y otro: "yo trabajaba en la refinería de dibujante, dibujaba tuberías, por dónde iba y todo el rollo ese, el plano. Y luego en una borrachera en la fiesta de un amiguete me cayó una máquina de tatuar" (HTR5). $\mathrm{Al}$ preguntar a un tatuador si de pequeño era un niño que dibujaba, su respuesta fue: "sigo siendo un niño que dibuja y espero serlo siempre" (HTR12).

Muchos entrevistados tienen necesidad de expresarse artísticamente más allá del tatuaje. En algunos casos así lo hacen: "mi vida artística es dibujar desde pequeño y en los años ochenta, con el grafitti encontré una salida artística a lo que yo estoy haciendo en casa. (...) empieza como camino de búsqueda mía constantemente del dibujo, la pintura, Hice aerografía en motos y eso lleva a la unión de todo en los tatuajes" (HTR2). En cambio hay quien está totalmente absorbido por el tatuaje: "me interesan las artes plásticas lo que pasa es que no puedo hacer nada más porque esto te come toda la...me gustaría hacer escultura, me gustaría ser arquitecto, pero esto te consume" (HTR1) y también hay quienes mantienen una actividad pictórica muy activa: "yo sigo pintando al óleo" (MTR3). En un estudio en Brooklyn me muestran la galería de arte y dicen: "somos pintores y tatuamos para ganar dinero y seguir pintando" (HTR19).

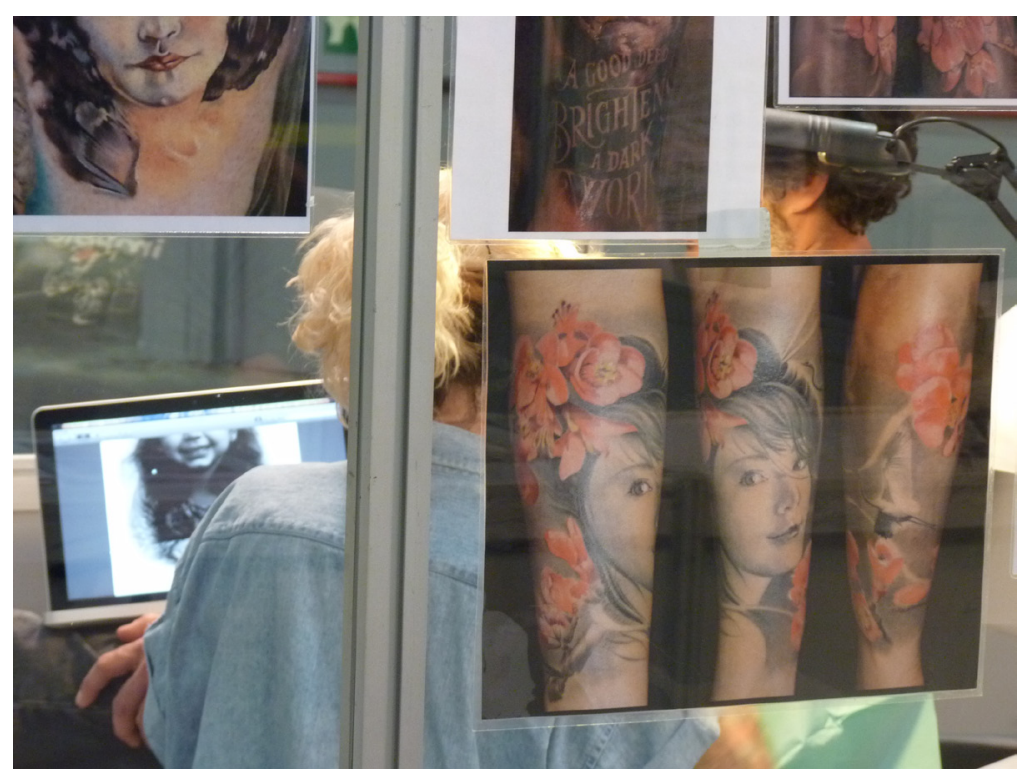

Figura 5. Laura Juan, tatuadora y pintora. 
Con respecto a la formación hay quienes reivindican unos estudios guiados: "pinto con óleo y sigo tomando clases con un gran profesor ...es una forma de no quedarte anclado aquí (...) hice también un curso de ilustración dos años y te sirve" (MTR3) o bien: "estudié arte y me dediqué al tattoo porque es la forma de vivir de un trabajo creativo" (HTR10). Sin embargo otros reivindican el no estar inducidos por maestros o escuelas: "yo no vengo de una escuela, a mí no me ha manipulado ningún profesor por así decirlo, porque tú te vas haciendo un poco con la técnica autodidacta" (HTR2). La cuestión autodidáctica está muy presente en el discurso de tatuadores senior: "me compré un catálogo en Italia porque aquí no había nada, y empecé a tatuarme las piernas. Lo tienes que sentir tú: una oreja de cerdo no sangra, no le duele...Tienes que sentirlo tú en tus propias carnes para practicar" (HTR1).

\section{2. ¿Arte, artesanía, profesión, oficio?}

Una entrevistada joven pone las cosas en perspectiva histórica: "hoy ya no se entiende como un oficio pero antes era un oficio. Empezabas muy pequeñito, te cogía un maestro y te enseñaba y a lo mejor te pasabas años soldando agujas, limpiando la tienda (...) Ahora son generaciones que empiezan más mayores, como veinte y algo, vienes de estudiar Bellas Artes y te metes en el mundo del tatuaje...también es que antes alguien te cogía de aprendiz o lo tienes muy difícil. Si Pablo te muestra su primera máquina de tatuar está hecha con una cuchara y un timbre. Yo me la hice con un bic y un radioasete. Pero hoy te puedes comprar por seiscientos euros una máquina en China y estar tatuando enseguida, y si encima sabes dibujar porque tienes estudios, lo tienes súper fácil" (MTR4). Es interesante este testimonio que da cuenta de cómo la popularización del tatuaje ha ido de la mano de la accesibilidad de las herramientas y de la formación académica de los nuevos tatuadores. Un tatuador pionero en España confirma esta percepción: "ahora lo que es artístico es mucho mejor, los jóvenes son más artistas de lo que yo jamás he sido, el primer tatuaje de un chaval es más arte que el último que hice yo (...) en los años setenta, ochenta, noventa, los que tatuábamos éramos más artesanos que artistas" (HTR14). Una tatuadora que da sus primeros pasos se refiera así a un tatuador con larga experiencia: "es un artesano porque él se arregla sus agujas, se hace su tinta negra, se hace su crema anestésica" (MTR2). La condición de artesano aparece reflejada en dos sentidos: el primero para referirse a los inicios más rudimentarios tanto técnica como artísticamente y también para valorar la realización personal y manual de ciertas tareas propias de la práctica del tatuaje.

Como se apreciará en el siguiente testimonio, la asociación del tatuaje con el arte aparece vinculada a los resultados: "el tatuaje ha evolucionado y ha dado más, yo creo, de lo que se esperaba. En el primer momento que se inventó una máquina para tatuar la gente no podía imaginar lo que ahora se hace, así que yo creo que hay que ponerlo más alto, se lo tiene merecido. Son muchísimos años y ya es un movimiento artístico (...) Así como a principio de los noventa el diseño gráfico y las artes gráficas no estaban consideradas como algo que se podía estudiar en una universidad, ahora ya es una carrera" (MTR3). Sin embargo, no todo el tatuaje puede considerarse como un hecho artístico: "nosotros ahora ya, al pasar a un movimiento artístico, hay dos tipos de estudio, es como los restaurantes: te puedes meter en un bar a comer cualquier tontería y luego te puedes ir al restaurante de un cocinero de renombre que 
vas a comer su comida degustación (...) aquí también ha habido diferencia: está el estudio donde se hacen ese tipo de tatuajes más de moda o ya el tatuaje más artístico" (MTR3).

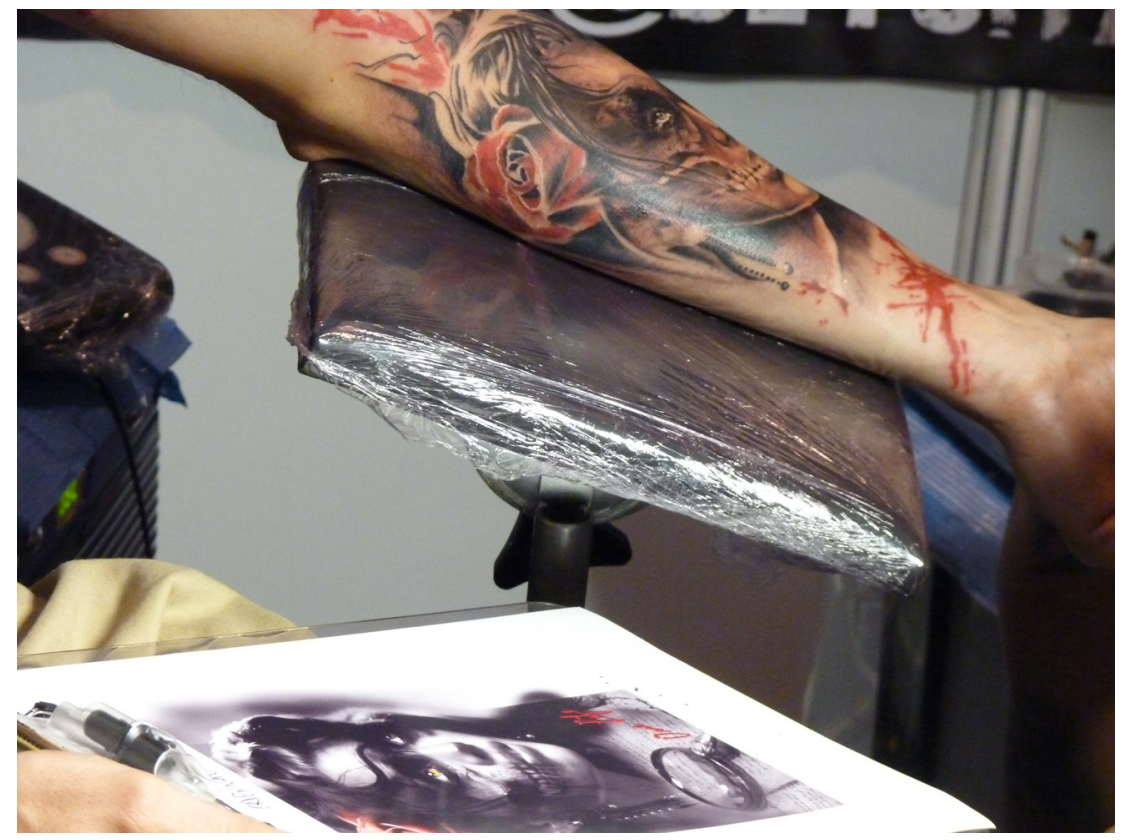

Figura 6. Tatuaje a partir de un modelo.

La diferenciación entre el tatuador artista y el artesano también se valora de acuerdo con la originalidad y la creación personal capaz de evitar el trabajo mecánico y repetitivo: "si solo coges flashes ${ }^{5}$ antiguos de los años veinte, le pones una hoja encima lo copias y luego lo tatúas... que sepas copiar no significa que sepas dibujar. Yo veo que tú no eres artista, tú eres artesano. (...) De hecho, la mayoría de todos nosotros tatuadores, somos artesanos. A lo mejor hay gente artista pero pocas veces te dan la oportunidad de ser artista. El artista es el que hace el águila y la serpiente sin basarse en nada (MTR4), o bien: "el tattoo es arte si creas pero si no creas es artesanía, copia" (MTR6).

Un entrevistado sitúa la cuestión artística en relación con la demanda: "en un porcentaje sí, cuando me dan la libertad de hacer lo que yo quiero, si no ya se convierte en un trabajo por encargo" (HTR4). La creatividad y el dominio técnico aparecen como argumentos de peso reiteradamente para determinar si el tatuaje es arte o no lo es: "el tatuaje es arte si lo hace alguien creativo y con dominio técnico. Pero en tatuaje no todo es arte" (HTR8).

Al parecer, las características de este fenómeno no se agotarían en determinar su cualidad artística: "el tatuaje es un arte por creatividad y por técnica, pero el tattoo es también algo espiritual y es una religión. Es espiritual para quien lo hace y también puede serlo para quien se lo hace. También funciona como una fábrica: uno detrás de otro. Hoy, por ejemplo, ya hice tres" (HTR9). 
Un tatuador estadounidense de prestigio mundial, tanto por su trabajo de tatuador como de pintor, y con su cuerpo densamente tatuado, lleva en la cara interna su brazo un tatuaje con una paleta de pintor y unos pinceles cruzando el diseño. Cuando se le interroga por ese tatuaje se disculpa aduciendo que es antiguo y que no es de buena calidad. Al repreguntarle si ese tatuaje responde a una ambición de ser artista, baja la mirada hacia su brazo y hace un gesto afirmativo con la cabeza.

Para concluir este apartado, veremos la opinión de un tatuador que ha sido considerado como uno de los cinco mejores del mundo: "todo es arte, incluso el tatuaje flash, cada uno hace lo mejor que puede. Al estar tan rodeados de imágenes uno se pregunta qué es copia y que no lo es.....En el fondo de todo está el amor. El amor es el arte más complicado y sin amor no hay nada más. El tatuaje es también un trabajo del amor" (HTR12).

\subsection{Tatuaje y autoría}

La cuestión de la autoría ha tenido un lugar muy importante en la definición del arte y también está presente en el discurso de tatuadores y tatuadoras. Un tatuador dice: "de lunes a jueves tatúo y los otros días voy a mi estudio y pinto, hago escultura y grabado. Últimamente colaboré en el diseño de ropa para Lady Gagá (...) para mí firmar no es lo más común pero tú imagínate que yo a veces tatúo dibujos míos y la gente me pide que lo firme. Quiere decir que la gente quiere llevar una obra mía y quiere llevar la firma...como que está orgulloso de llevarlo. Entonces más orgulloso que me siento yo no podría ser" (HTR2).

El reconocimiento del trabajo personal e identificable por estilo con un autortatuador es algo altamente valorado porque supone haber alcanzado un sello personal y un renombre: "si te muestro mis trabajos sabes que es mío sin decirte que lo he hecho yo (...) Mi firma es mi estilo, cómo lo plasmo. Yo no firmo con mi nombre porque no es un cuadro" (HTR1), y otro: "hoy por hoy la diferencia entre uno bueno y uno mediocre es que ves un tattoo y sabés de quien es" (HTR3).

La autoría puede producir, entre las personas más compenetradas con el mundo del tatuaje, desplazamientos e inversiones importantes de dinero: "más de una vez he cogido un avión para ir a tatuarme con alguien que admiro" (MTR10). También puede fomentar la actitud coleccionista: "un coleccionista es alguien que busca a un artista, que no le importa pagar por una pieza lo que debe" (MTR5), o incluso: "me tatúo independientemente del diseño porque lo que quiero es tener en mi cuerpo la obra de un artista que me gusta y punto" (MTR11).

\subsection{Analogías entre tatuaje y artes visuales}

La incorporación de personas con formación artística dentro del mundo del tatuaje y la consecuente mejora de la técnica, la calidad y la variedad de estilos y diseños puede ser una de las causas por las que el discurso esté plagado de referencias al arte. En algunos casos aparece integrado de forma espontánea en la expresión oral y en otros responde a un intento de explicar las características del tatuaje en relación a las artes más clásicas: "igual que de repente empezaron a surgir esos pintores como Sorolla que la gente de un nivel alto iba a verlos a sus casas porque necesitaba unos 
retratos, pues ahora es el tatuaje pero para otro tipo de gente, bueno...no sé si para otro tipo de gente porque la verdad es que el tatuaje bueno es un artículo de lujo, no es barato" (MTR3). Otra analogía con las artes visuales aparece en este testimonio: "hay gente que sí que entiende que el tatuaje es un arte y, por tanto, tú puedes coleccionar arte (...) eso cuesta dinero: yo he viajado, me he ido a otro continente, me he tatuado con la persona que quería y he vuelto, eso es algo que a lo mejor otro lo haría por un cuadro o unas litografías que te gustan y te pones a pujar y estás de madrugada pujando" (MTR4).

En la comparación entre tattoo y arte, surge también un tema clásico de la estética como es el del gusto: "en el tatuaje, como en todo tipo de arte, hay cosas que son difíciles de juzgar. A mí hay artistas que me gustan muchísimo y artistas que no me gustan nada. Velázquez me gusta muchísimo y Miró no me gusta nada...es cuestión de gustos" (HTR3).

Entre quienes siguen trabajando en otras disciplinas visuales, los intercambios entre la obra pictórica y los tatuajes aparecen muy presentes: "mi estilo es más cercano a lo que pinto en los cuadros, es más pictórico, más colorista, se aleja un poco de la línea tradicional del tatuaje (...) Mucha gente imita lo que hacían los tatuadores pero yo lo que he hecho es coger una técnica de pintura y aplicarla al tatuaje" (HTR13). La traslación de géneros pictóricos es vista como innovación y maestría en su traducción estilística y técnica sobre la piel: "hay gente que te hace unas aguadas, unas sombras y te hacen como imitar el efecto de la acuarela que es transparente, jeso en la piel! Eso lo están haciendo las nuevas generaciones porque saben dibujar" (MTR4).

Esta versatilidad y este ida y vuelta entre ámbitos no solo es evidente en el discurso sino que se hace presente con contundencia en los propios salones de tatuaje ya que muchos de ellos incluyen una zona de exposición de obra pictórica, gráfica y escultórica realizada bien por tatuadores o bien por artistas visuales, en ocasiones muy próximos a los modos y motivos del tatuaje. Esta práctica está ampliamente extendida en Estados Unidos y en España también puede verse, aunque en menor medida. Sin embargo, un entrevistado relata un hecho inverso: "Javier de Juan hizo unos dibujos de tatuajes para una exposición que se hizo en paralelo a las primeras exposiciones de ARCO en las que la gente se podía tatuar un diseño de Javier de Juan tatuado por mí y además si se tatuaban se lleva el dibujo original. Eso que yo sepa no se ha hecho en ninguna parte. Eso fue en la galería Moriarty, una galería con nombre muy conocido en Madrid (...) nosotros tatuábamos con gente alrededor que estaba en traje y corbata, en blue jeans o en abrigo de piel" (HTR14).

La dificultad actual para definir qué es y que no es arte parece afectar también al campo del tatuaje: "si a un cuadro lo consideras arte, esto es lo mismo: es arte sobre la piel. [repregunta: ¿cualquier tatuaje es arte, cualquier cuadro es arte?] Vale: paso palabra. Antes los conceptos estaban más marcados y las directrices estaban puestas. Si yo voy al Reina Sofía ¿todo es arte?...yo creo que hay gente que vende aire (...) $\mathrm{O}$ vas y dices: un Picasso, un Dalí jostia esos relojes derretidos! Pero ves un Goya o un Velázquez y ¡coño!, es que este no ha pintado lo mismo ijoder!, esos colores, esos volúmenes ¡Ostia colega!, al que se le ha ocurrido esto es un máquina y los demás somos meros observadores" (HTR15). 


\subsection{Lo específico del tatuaje}

Una de las características específicas y con gran peso en la ejecución del tatuaje está dada por el simple hecho de que el tatuaje se realiza sobre la piel, sobre el cuerpo de una persona. Dice una tatuadora novel: "estoy aprendiendo muchísimo (...) cómo aconsejarte si tienes un tipo de color de piel u otro, si tienes una cicatriz no puedes hacer ciertas cosas, el tipo de sitio donde quieras un tatuaje, cómo pinchar...A la hora de dibujar tienes que aprender a dibujar de otra forma, ya no puedes dibujar como en un papel, tienes que aprender composiciones" (MTR11).

Tatuar, es además, una actividad que no admite mucho margen de error lo cual supone una exigencia de perfección para quien lo ejecuta: "si no sabes dibujar no puedes tatuar. He roto muchos dibujos y muchos cuadros porque he pensado que se podían mejorar. Es muy frustrante eso. Pero en tatuaje, lo hecho hecho está y te salga como te salga no lo puedes romper, no lo puedes, arreglar, no lo puedes cambiar. Tiene esa magia especial de que lo hecho está hecho para siempre. Entonces puedo llegar a dar el $100 \%$ en ese momento, que no lo doy si estoy dibujando o pintando un cuadro" (HTR1). Un tatuador muy reputado lo expresa así: "cuando tatúo lo más importante es hacer bien mi trabajo, no pienso en arte ni en estilo. Si pensara que lo que estoy haciendo sobre la piel de mi cliente es algo que va a durar para siempre, quizás me intimidaría. Simplemente pienso en hacer bien mi trabajo" (HTR12).

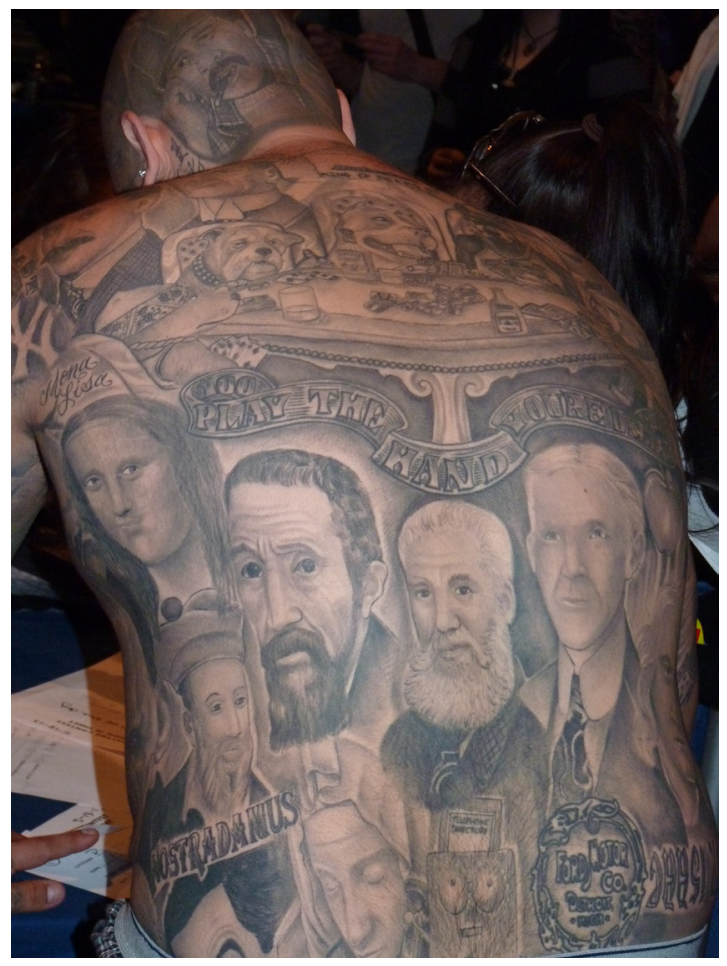

Figura 7. "Overall tattoo" es la denominación de las personas que llevan todo su cuerpo tatuado. 
En lo referido al dominio técnico que es necesario tener para tatuar con propiedad, el abanico de elementos específicos es amplio. Por un lado hay aspectos instrumentales: "si no sabes dibujar coges un lápiz y pinta pero si no sabes tatuar la tinta no se queda en la piel" (HTR1). El carácter casi definitivo del tatuaje ha hecho que en el pasado la formación de los tatuadores fuera muy peculiar: "muchos de los viejos tatuadores llevamos un tatuaje en la pierna porque es el lugar más fácil de tatuar (...) He visto piernas llenas de puntitos de color. Eso ya no se hace. Ahora se empieza con una oreja de cerdo, con muchas cosas. Yo la primera línea que hice fue en una naranja y después, al momento, me tatué la pierna" (HTR14). Otro aspecto vinculado con la técnica y práctica del tatuaje está relacionado con la forma de "pinchar" y con la conducta de la tinta una vez que entra en el cuerpo "las líneas y los sombreados tienden a juntarse con el tiempo, eso hay que saberlo, saber el grosor y la distancia de las líneas para que no quede un manchurrote" (MTR 12). También las distintas partes del cuerpo tienen conductas diferentes a lo largo de los años "quiero tatuarte en una parte del cuerpo que envejezca bien (...) yo quiero que mi obra envejezca bien" (HTR1), o: "la piel tiene una alteración con el tiempo, es tejido vivo coloreado, no es algo inalterable, entonces tenés que tener el suficiente conocimiento para que el tatuaje no quede buenísimo ahora y sea una mierda en cinco años" (HTR3). Otro aspecto central es el de la anatomía: "el papel es plano y el cuerpo es curvo (...) hay que estudiar el cuerpo humano leyendo libros, viendo muchos tatuajes, cómo fluyen, cómo quedan en el cuerpo, a base de mucha práctica" (HTR1). Dice una tauadora: "yo dibujo en papel y la técnica no es para nada parecida a transmitirlo en una piel, en un cuerpo que tiene curvas, está blando, que está vivo y notas que está vivo" (MTR13).

Pero en tatuaje no todo es destreza, talento y experiencia: "tiene que tener una parte artística, una parte de emoción y una parte de camilla, de limpieza" (HTR2). En efecto, los aspectos sanitarios tienen una presencia muy peculiar en el ámbito del tatuaje y existen regulaciones nacionales y autonómicas, en algunos casos estrictísimas. Otro aspecto específico del tatuaje es la relación cuerpo a cuerpo que se establece durante la sesión de tatuaje y la confianza que supone encargar a alguien que realice una inscripción indeleble sobre la carne: "es que es algo que haces para una persona, un trocito de tu energía esa persona lo va a llevar para siempre con él" (MTR9). Para algunos ese momento es mágico: "la magia no se puede definir, la tienes que sentir. Hay una complicidad entre el tatuador y el tatuado. Eso no se crea con ningún otro tipo de arte" (HTR1). En algún caso la valoración de ese lazo llega a ser comparado con otros propios de tradiciones ancestrales: "tú creas un vínculo con esa persona: tú le estás haciendo sangrar igual que los chamanes hacían sangrar para liberar ese tipo de energía y yo sí que tatúo y noto que la gente libera energía" (HTR17).

\section{Conclusiones}

El objeto de este trabajo no es determinar si el tatuaje en su estado actual puede o debe considerarse como una disciplina artística sino entrever los modos en los que la cuestión del arte aparece enunciada en los discursos de tatuadores y tatuadoras. Por medio de fragmentos de discurso se ha podido comprobar de qué manera elementos 
originariamente asociados a las artes visuales aparecen entremezclados en el discurso sobre el tatuaje. Lo bello, lo personal, lo político, lo virtuoso, el cuerpo como medio, como lienzo, como obra de arte, como colección, como inversión, como seducción, constituyen expresiones fácilmente atribuibles al campo artístico que también están presentes. Asimismo se ha podido constatar que hay cuestiones específicas que solo son propias del universo del tatuaje.

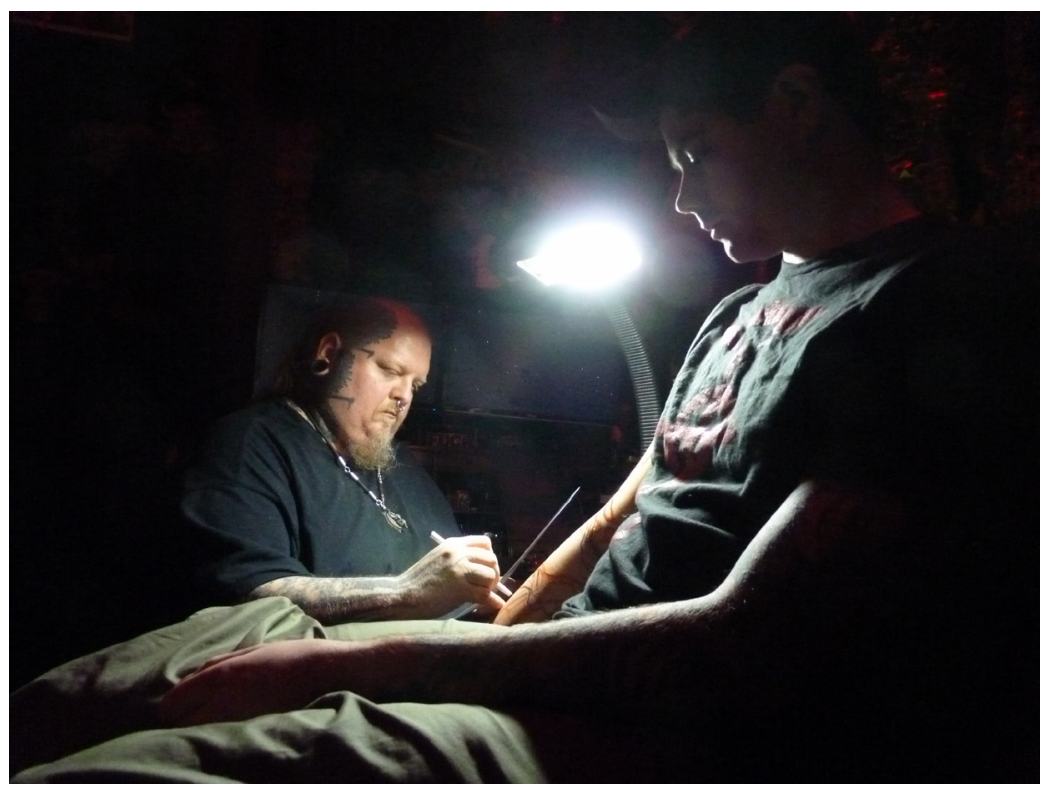

Figura 8. Tatuador Paul Booth trabajando en su estudio de New York.

Es innegable que existen préstamos e intercambios muy fuertes entre el mundo del tatuaje y el de las artes plásticas. Un ejemplo notable es el del tatuador estadounidense Paul Booth quien fue invitado en 2005 a incorporarse como miembro del National Arts Club, institución centenaria y prestigiosa. Booth, además de ser uno de los más reputados tatuadores es reconocido como pintor y creador del movimiento Art Fusion con Filip Leu. Su salón de tatuaje en Nueva York se llama: "Last rites tattoo theatre" y en él hay una galería de arte con un galerista a cargo y también un escenario en el cual artistas invitados pueden participar de sesiones de Art Fusion compartiendo lienzo en el cual trabajan y componen juntos. De otro lado, un tatuador de renombre como Anil Gupta cuenta, entre una de sus especialidades, la del tatuaje miniaturizado de obras de arte famosas de Dali, Klimt, Van Gogh, Da Vinci, entre otros ${ }^{6}$.

Como explica Martínez Rossi, la piel es en cada sociedad y en cada cultura una superficie simbólica, lugar de inscripción que desborda lo meramente biológico y se activa como texto, "irónicamente, esta revelación a través del cuerpo, a nivel de superficie, cala en lo más hondo de cada sociedad y cultura" (Martínez Rossi:2011:450). Las manifestaciones discursivas, tanto se trate de expresiones textuales o visuales, sean estas populares, masivas, mediáticas o artísticas, también se hacen carne y hacen carne en lo profundo de una sociedad y un tiempo. 
El arte corporal de larga data encuentra en las sociedades globalizadas nuevas modulaciones que recrean, reinterpretan y transforman, embebidas en el actual espíritu de la época, motivaciones antropológicas, políticas, estéticas. El actual desarrollo del tatuaje, tanto desde el puno de vista de su ejecución, sus motivos, técnicas y estilos, la creación de una actividad profesional y un mercado, la formación, destreza y ambición creativa de quienes los realizan y quienes se tatúan, constituye un dato ineludiblemente visible en el que observar, como en el Aleph borgiano, un punto que contiene a los demás.

\section{Referencias}

Aumont, J. (1998) La estética hoy. Madrid: Cátedra.

Borges, J.L. (1996) El Aleph; en Obras completas I. Barcelona: RBA- Instituto Cervantes.

Belting, H. (2007) Antropología de la imagen. Buenos Aires: Katz editores.

Blanchard, M. (1994) Post-burgeois tattoo. Reflections on skin writting in late capitalist societies. En Taylor Lucien (Ed) Visualizing theory. Selected essays from V.A.R 1990-1994. New York: Routledge.

Danto, A. (2013) What art is? New Heaven \& London: Yale University Press.

Hart, C. (2010) Tatuado. Alemania: H.F. Ullman.

Jones, A. (2006) El cuerpo del artista. London, New York: Phaidon.

Martínez Rossi, S. (2011) La piel como superficie simbólica. Procesos de transculturación en el arte contemporáneo. España: Fondo de cultura Económica

Mirzoeff, N. (1995) Bodyscape. Art, modernity and the ideal figure. New York: Routledge.

Páez Sodely (2011) El cuerpo y sus usos en el arte contemporáneo. Recuperado de http://criticalatinoamericana.com/el-cuerpo-y-sus-usos-en-el-artecontemporaneo/ el 1 de julio de 2014.

Rubin, A. (1987) Marks of civilization. Artistic transformations of the human body. Los Ángeles: Museum of cultural History, University of California.

Tatarkiewicz, W. (2002) Historia de seis ideas: Arte, belleza, forma, creatividad, mímesis, experiencia estética. Madrid: Tecnos Alianza.

Weintraub L., Danto A., McEvilley, T (1996) Art on the edge and over. Searching for art's meaning in contemporary society 1970-1990s. New York: Arts insights, Inc. Publishers.

Zátonyi, M. (2000) Aportes a la estética desde el arte y la ciencia del siglo XX. Buenos Aires: Biblioteca de la mirada.

\section{Notas}

1. Hoy los artistas violan convenciones una vez consideradas fundamentales para el arte. Su trabajo plantea cuestiones tales como: jes arte si no está en un pedestal ni cuelga de una pared?, ¿Es arte si no es el producto del trabajo de la mano del hombre? ¿Es arte si no es el resultado de un momento de inspiración?, ¿si no es duradero o placentero? ¿si la estimulación visual no es la principal preocupación del artista? 
2. En 2007 el New York Times publicó que en los Estados Unidos había 45 millones de personas tatuadas (citado por Hart,2010:23) sobre un total de 307 millones de habitantes. Evidentemente es difícil hacer estadísticas muy ajustadas a este respecto, pero si estos datos tienen cierta credibilidad, es lícito suponer un gran incremento de estas cifras en los últimos años. La cantidad de personas tatuadas en el mundo es incalculable pero llega, al menos, a varios cientos de millones.

3. "El cuerpo ha sido el tema principal en el arte occidental desde el Renacimiento. Al mismo tiempo, es también un locus central y una metáfora para la comprensión y la exploración del cambio político (...) El período moderno se puede caracterizar por tener conciencia de que el cuerpo es mutable, incompleto y completamente humano. Esta sensación alarmante de inestabilidad ha dado lugar a numerosos esfuerzos para controlar el desarrollo del cuerpo físico mediante la promoción de ciertas características físicas a expensas de los demás. El sentido postmoderno del cuerpo es la realización de los costes y de las debilidades de este tipo de proyectos Utópicos"

4. Mulafest es un evento anual que contiene a la Convención de tatuadores de Madrid.

5. El tatuaje flash es el que se realiza copiando de un catálogo y plasmándolo sobre la piel a partir de un calco.

6. Se sugiere ver la página web: www.anilgupta.com en la que en la entrada "portfolio" hay una específica denominada "fine arts". 